GMR

\title{
Colored fiber cotton in the Uberlândia region using artificial neural networks for yield assessment
}

\author{
D.B.O. Cardoso ${ }^{1}$, E.G.Silva Júnior ${ }^{4}$, M.C. Reis ${ }^{3}$, L.B. de Sousa ${ }^{2}$, \\ L.M. S. Falco ${ }^{5}$, M.C. Mamede', B.Q.V. Machado', T.S. Paiva ${ }^{2}$, \\ C.P. Gundim ${ }^{6}$, G.A. Alves ${ }^{2}$ and L.P. de Araújo ${ }^{7}$ \\ ${ }^{1}$ Agronomia, Instituto de Ciências Agrárias, Universidade Federal de \\ Uberlândia, Uberlândia, MG, Brasil \\ ${ }^{2}$ Instituto de Ciências Agrárias, Universidade Federal de Uberlândia, \\ Uberlândia, MG, Brasil \\ ${ }^{3}$ Fundação Mato Grosso, Rondonópolis , MT, Brasil \\ ${ }^{4}$ Tropical Melhoramento \& Genética (TMG), Rondonópolis, MT, Brasil \\ ${ }^{5}$ Centro Universitário do Triângulo, Uberlândia, MG, Brasil \\ ${ }^{6}$ Compania da Terra Agronegócios LTDA., Uberlândia, MG, Brasil \\ ${ }^{7}$ College of Agriculture, Food and Environment., Lexington, KY, EUA \\ Corresponding author: D.B.O. Cardoso \\ E-mail: danieludia13@hotmail.com
}

Genet. Mol. Res. 18 (1): gmr18104

Received August 06, 2018

Accepted December 26, 2018

Published January 31, 2019

DOI http://dx.doi.org/10.4238/gmr18104

\begin{abstract}
Cotton is the most widely utilized natural fiber in the world. Brazil is currently one of the world's largest cotton producers. Cotton crops are cultivated in all regions of the country, especially in the Cerrado biome. Studies of genotype $\mathrm{x}$ environment (GxE) interactions evaluate the adaptability and stability of cotton genotypes. Adaptability and stability evaluations help understand genotype responses to environmental stimuli and the predictability of genotypes in their response to environmental oscillations. We examined the effect of the genotype $\mathrm{x}$ environment interaction on cotton yield and fiber characteristics and compared artificial neural networks (ANNs) with conventional methods for assessing adaptability and stability of colored-fiber cotton genotypes. The experiment was conducted at the experimental farm of Universidade
\end{abstract}


Federal de Uberlândia, during four crop years. Twelve genotypes of colored-fiber cotton were evaluated. The experimental design was randomized complete blocks with three replicates. Seed cotton yield was evaluated. The GxE interaction was analyzed by the F-test at $\alpha=$ 0.05. Adaptability, stability, and the factors of the decomposed GxE interaction were analyzed by the Eberhart and Russell, Centroid and ANN methods. The GxE interaction was significant for the variable seed cotton yield, demonstrating differences in genotype behavior among environments. The interactions were predominantly complex. There was concordance between Eberhart and Russsell and ANN analyses. Genotypes UFUJP-02 and UFUJP-17 were responsive to environmental stimuli; they had high predictability, in addition to high fiber yield. The ANN method reliably evaluated adaptability compared with Eberhartand Russel and Centroid methods.

Key words: Computational intelligence; Gossypium hirsutum; stability; adaptability

\section{INTRODUCTION}

Brazil currently ranks fifth among world cotton producers, with an estimated cultivated area of more than 1 million hectares in the 2017/2018 growing season (USDA, 2018). Colored-fiber cotton has a high marketability potential in Minas Gerais state since it has a higher aggregate value than white-fiber cotton and it has a relevant socioeconomic impact in this state.

Plant breeding is an efficient tool to obtain more productive and adapted cultivars for each environment; this facilitates reductions in input costs and maximizes the profit of the production system. Studies of genetic behavior in different environments are imperative because the interaction between genotypes and environments (GxE) directly affects the phenotypic manifestation of the genotypes (Cruz et al., 2014). Consequently, the GxE interaction complicates the plant breeding process.

However, study of these interactions does not always provide sufficient information about genotype behavior under different environmental conditions (Cruz et al., 2014). Such studies should be complemented with adaptability and stability analyses, which can provide detailed information on genotype behavior and provide information about predictability and improvement responses in these environments (Cruz et al., 2014).

There are several methods to evaluate the adaptability and stability of genotypes. These methods rely on the nature of the variables, number of environments, required precision, among other factors. One of the most widely used methods is Eberhart and Russell's (1966), which utilizes a linear regression model. The modified Centroid is another commonly utilized method (Nascimento et al., 2009), which consists of comparisons between values of the average distance from genotypes to seven ideotypes in a Cartesian plane. Barroso et al. (2015) conclude that the Centroid methodology can be complemented by Eberhart and Russell's methodology. However, there are limitations when utilizing this complementation in studies involving few environmental conditions. 
Artificial neural networks (ANN) methodology is an alternative to overcome the limitations imposed by Eberhart and Russell's (1966) predefined classes. ANNs are similar to networks of neurons that process considerable data, recognize patterns and possess a selflearning capacity. In addition, simulation of data in ANNs leads to their own training and validation and organizes large genotype collections according to predefined classes (Haykin, 2009; Nascimento et al., 2013). Junior et al. (2017) utilized ANNs to select for high fiber quality in cotton genotypes.

We examined the effect of GXE interactions on cotton yield and assessed the ANN method in the analysis of adaptability and stability of colored-fiber cotton genotypes.

\section{MATERIAL AND METHODS}

The study was conducted in the city of Uberlândia, Minas Gerais (18 $52^{\prime}$ 'S; $48^{\circ} 20^{\prime} \mathrm{W}$ and $805 \mathrm{~m}$ of altitude) during2013/2014, 2014/2015, 2015/2016, and 2016/2017 growing seasons.According to climatic data (1981 to 2008) provided by the Institute of Geography of Universidade Federal de Uberlândia, Uberlândia has an average air temperature of $22.4^{\circ} \mathrm{C}$, a mean relative humidity of $70 \%$ and an average annual rainfall of $1,584 \mathrm{~mm}$. The meteorological conditions during this study were monitored by an automatic weather station that provides temperature and rainfall data (Figures1 to 4).

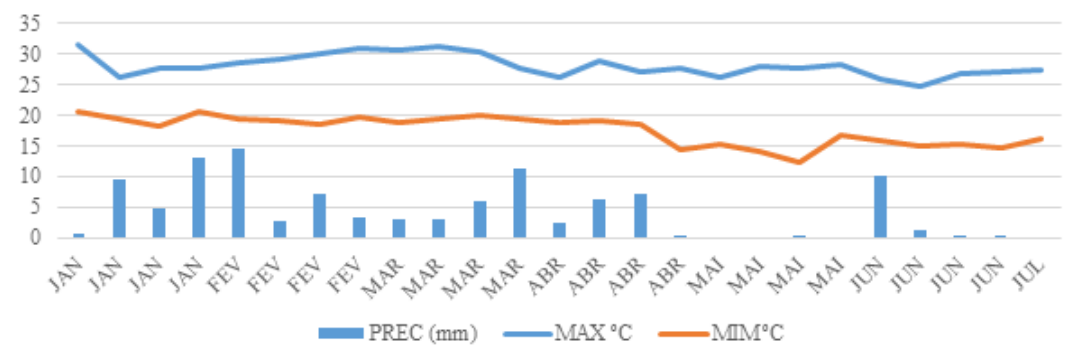

Figure 1. Meteorological data from $12 / 2013$ to $06 / 2014$

$\operatorname{MAX}\left({ }^{\circ} \mathrm{C}\right)$ - Maximum temperature; $\operatorname{MIN}\left({ }^{\circ} \mathrm{C}\right)$ - Minimum temperature; Prec (mm) - Precipitation.

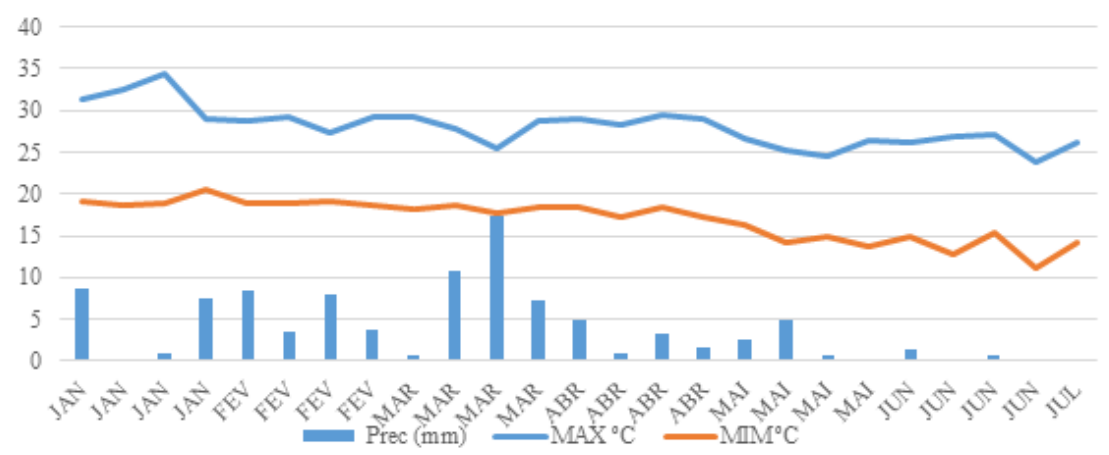

Figure 2. Meteorological data from 12/2014 to 06/2015

MAX $\left({ }^{\circ} \mathrm{C}\right)$ - Maximum temperature; $\operatorname{MIN}\left({ }^{\circ} \mathrm{C}\right)$ - Minimum temperature; Prec $(\mathrm{mm})$ - Precipitation. 


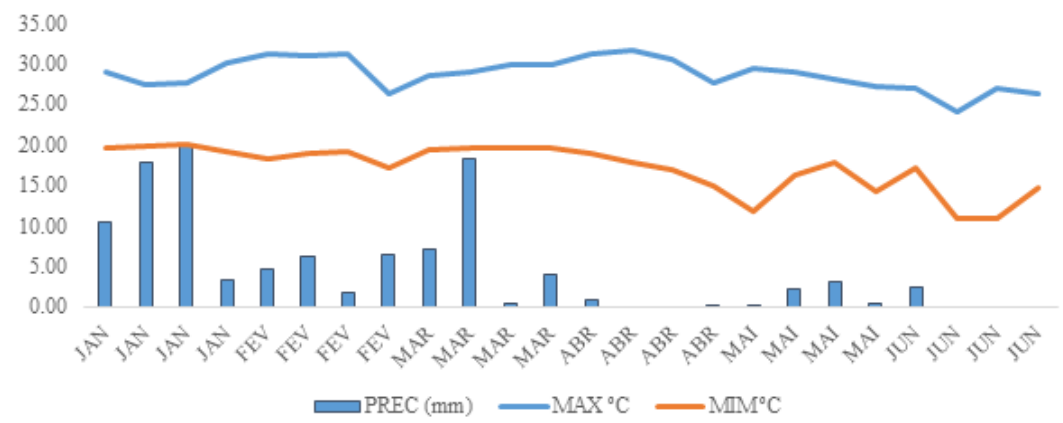

Figure 3. Meteorological data from $12 / 2015$ to $06 / 2016$

MAX $\left({ }^{\circ} \mathrm{C}\right)$ - Maximum temperature; MIN $\left({ }^{\circ} \mathrm{C}\right)$ - Minimum temperature; Prec (mm) - Precipitation.

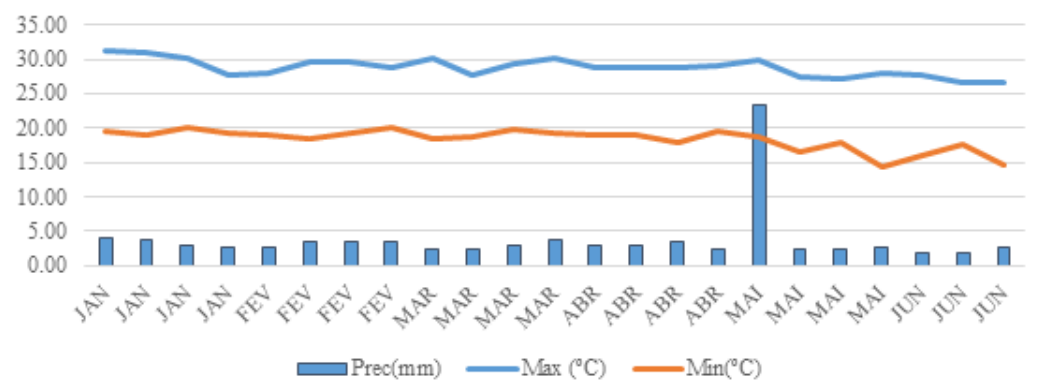

Figure 4. Meteorological data from 12/2016 to 06/2017

MAX $\left({ }^{\circ} \mathrm{C}\right)$ - Maximum temperature; MIN $\left({ }^{\circ} \mathrm{C}\right)$ - Minimum temperature; Prec $(\mathrm{mm})$ - Precipitation.

The study was conducted in a clay texture soil designated as Orthic Ferralsols. A composite soil sample was collected before the study implementation for chemical analysis, and for liming and fertilization recommendations.

The soil preparation was performed using a conventional tillage system consisting of one plowing and two harrowing operations. Furrows were plowed across the area and fertilization was done with NPK 20-80-10. Seeding was in December, with a rate of 16 seeds per meterat $2 \mathrm{~cm}$ depth. At 30 days after emergence, experimental plots were thinned to eight plants per meter andside-dressedwith $80 \mathrm{~kg}$ of $\mathrm{N} \mathrm{ha}^{-1}$.

Twelve genotypes of colored-fiber cotton were evaluated. Ten of these genotypes originated from the Programa de Melhoramento Genético do Algodoeiro (PROMALG): UFUJP-01, UFUJP- 02, UFUJP-05, UFUJP-08, UFUJP-09, UFUJP - 10, UFUJP - 11, UFUJP - 13, UFUJP - 16, UFUJP -17 in the F6 generation. The two remaining genotypes were the commercial cultivars BRS Rubi (RC) and BRS Topázio (TC).

The experimental design was randomized complete blocks (RCBD) with three replicates. The experimental plot consisted of four rows, five meters long, spaced one meter apart. The plots useful area comprised two central lines and $0,5 \mathrm{~m}$ was discarded from each end of the plots.

Weed control was performed both manually and chemically. Dual Gold (SMetalachlor) was applied pre-planting. The herbicide Staple (Pyrithiobac-Sodium) was applied in the area. Several applications of phytosanitary products were made to achieve pest management. The main pests found in the plots included the Silver leaf Whitefly 
(Bemisiata baci), the Boll Weevil (Anthonomus grandis), Thrips (Frankliniella spp.), Cotton Stainer (Dysdercus ruficollis), Tobacco Budworm (Chloridea virescens), Soybean Looper (Chrysodeixis includens), Cotton Leafworm (Alabama argillacea), and the Two spotted Spider Mite (Tetrany chusurticae). Sequential applications with the growth regulator Mepiquat chloride were made throughout the crop growing season (1,1-dimethylpiperidinium chloride).

At full maturation of the crop, five plants from the useful area of the plots were randomly selected to assess the following parameters:

Seed Cotton Yield: collection and weighing of all open bolls in the useful area of each plot $\left(\mathrm{kg} \mathrm{ha}^{-1}\right)$.

For statistical analysis, we performed tests for homogenity of residual variances (Levene's Test), additivity (Tukey'stest), and normality of residuals (Shapiro-Wilk). The homogenity of residual variances was also tested by the ratio between the largest and the smallest residue mean square (MSE), which cannot be higher than seven to perform joint variance analysis (Cruzet al., 2014). Subsequently, we performed a joint variance analysis assuming genotype and environment as fixed factors.

The GxE interaction was decomposed into simple and complex parts following Cruz and Castoldi's (1991) method, given by the expression:

$$
\begin{gathered}
Q M G * A=S+C \\
C=\sqrt{(}(1-r)^{3} Q_{1} Q_{2}
\end{gathered}
$$

Where:

$\mathrm{S}=100-\mathrm{C}$

$\mathrm{r}=$ correlation between genotype means in both environments, $\mathrm{Q}_{1}$ and $\mathrm{Q}_{2}$.

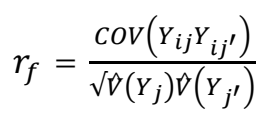

Where:

$\operatorname{COV}\left(\left(Y_{i j} Y_{i j^{\prime}}\right)\right.$ : Phenotypic covariance of the characteristic $\mathrm{X}$ evaluated in environment $\mathrm{j}$ and $\mathrm{j}^{\prime}$;

$\widehat{V}\left(Y_{j}\right)$ : Phenotypic variance of characteristic $\mathrm{X}$ in environment $\mathrm{j}$;

$\widehat{V}\left(Y_{j}\right)$ : Phenotypic variance of characteristic $\mathrm{X}$ in environment $\mathrm{j}$;

Eberhart and Russell's (1966) method was used for adaptability and stability analysis. This method utilizes a simple linear regression of genotypes to determine parameters of adaptability and stability according to the following linear model:

$$
Y_{i j}=\beta_{0 i}+\beta_{1} i+I_{j}+\delta_{i j}+\overline{\varepsilon_{i j}}
$$

Where:

$Y_{i j}$ : Average of genotype $\mathrm{i}$ in environment $\mathrm{j}$;

$\beta_{0 i}$ : general average of genotype;

$\beta_{1 i}$ : Linear regression coefficient, which measures the response of genotypei to environmental variation;

$I_{j}$ : coded environmental index $\left(\sum I_{j \mathrm{i}}=0\right)$;

$\delta_{i j}$ : regression deviation

$\overline{\varepsilon_{i j}}$ : Average experimental error 
To obtain ideal values, regression coefficients $\left(\beta_{1}\right)$ must be equal to 1 , which means broad overall adaptability. Regression coefficients lower than 1 represent genotypes with better development under less favorable environments; regression coefficients higher than 1 represent genotypes with better development in more favorable environments. Regression coefficients with values close to 0 demonstrate high predictability and stability $\left(\sigma_{\mathrm{di}}^{2}\right)$ of genotypes (Cruz et al., 2014). Consequently, the smallest regression deviation coefficients are desirable, as displayed in Table 1

$$
\begin{gathered}
\sigma^{2} \mathrm{di}=\sum_{j} \delta_{l j} /(a-2) \\
\mathrm{B}_{1 \mathrm{i}=} \frac{\sum_{j} Y_{i j} I_{j}}{\sum_{j} I^{2}{ }_{j}}
\end{gathered}
$$

Table 1. Classes of genotypes using the Eberhart and Russell's (1966) methodology and their respective parametric values.

\begin{tabular}{lcc}
\hline Classes & Practical Classification & Parametric values \\
\hline 1 & General adaptability and low predictability & $\beta_{1 \mathrm{i}}=1 \mathrm{e} \sigma_{\mathrm{di}}^{2}>0$ \\
2 & Specific adaptability to favorable environments and low predictability & $\beta_{\mathrm{li}}>\mathrm{e} \sigma_{\mathrm{di}}^{2}>0$ \\
3 & Specific adaptability to unfavorable environments and low predictability & $\beta_{1 \mathrm{i}}<1 \mathrm{e} \sigma_{\mathrm{di}}^{2}>0$ \\
4 & General adaptability and high predictability & $\beta_{1 \mathrm{i}}=\mathrm{e} \sigma_{\mathrm{di}}^{2}=0$ \\
5 & Specific adaptability to favorable environments and high predictability & $\beta_{\mathrm{li}}^{2}>1 \mathrm{e} \sigma_{\mathrm{di}}^{2}=0$ \\
6 & Specific adaptability to unfavorable environments and high predictability & $\beta_{\mathrm{li}}<1 \mathrm{e} \sigma_{\mathrm{di}}^{2}=0$ \\
\hline
\end{tabular}

The Centroid method (Rocha et al., 2005) is a non-parametric estimate of adaptability and stability. This method utilizes a multivariate technique that allows reducing the data set size with minimal loss. This method compares distance values in the Cartesian plane between genotypes and ideal references (ideotypes). The ideotypes are inferred from the experimental data to represent the genotypes of maximum overall adaptability, maximum specific adaptability to favorable or unfavorable environments, and the genotypes of minimum adaptability. The environments were classified as favorable or unfavorable according to the environmental index proposed by Finlay and Wilkinson (1923) (Nascimento et al., 2009).

$$
I_{j}=\frac{1}{g} \Sigma Y_{i j}-\frac{1}{a g} Y
$$

Where:

$\mathrm{Y}_{\mathrm{ij}}$ : $\mathrm{i}$ genotype average in environment $\mathrm{j} ; \mathrm{Y}$ : total observations; $\mathrm{a}=$ number of environments; $\mathrm{g}=$ number of genotypes. The software Genes was utilized for this analysis (Cruz, 2016).

Two data sets were utilized to evaluate the adaptability and stability of genotypes by the ANNs method: the training set and the validation set. Both training and validation sets were obtained by simulating 3,000 genotypes across four environmental conditions, according to the defined classes. The parametric values used for each one of the classes 1,2, and 3 were composed of500 genotypes and were defined according to the following:

Class 1: $\beta_{0 \mathrm{i}}=\overline{\mathrm{X}}_{\mathrm{G}}, \beta_{1 \mathrm{i}} \sim \mathrm{U}[0.90 ; 1.10]$ and $\sigma^{2}=250$, i.e., $\beta_{1 \mathrm{i}}$ is considered equal to 1 if $\beta_{1 \mathrm{i}} \in[0.90 ; 1,10]$;

Class $2: \beta_{0 \mathrm{i}}=\overline{\mathrm{X}}_{{ }_{\mathrm{G}}}, \beta_{\mathrm{li}} \sim \mathrm{U}[1.11 ; 2.00]$ and $\sigma_{\Psi}^{2}=250$, i.e., $\beta_{1 \mathrm{i}}$ is considered higher than 1 if $\beta_{1 i} \in[1.11 ; 2.00]$; 
Class 3: $\beta_{0 \mathrm{i}}=\overline{\mathrm{X}}_{4 \mathrm{G}}, \beta_{1 \mathrm{i}} \sim \mathrm{U}[0.00 ; 0.89]$ e $\sigma^{2}=250, \sigma^{2}{ }_{\Psi}=250$, i.e., $\beta_{1 \mathrm{i}}$ is considered less than 1 if $\beta_{1 i} \in[0.00 ; 0.89]$;

$\mathrm{U}[\mathrm{a} ; \mathrm{b}]$ represents the distribution of the continuous uniform probability with the parameters a and $b$. From these parametric values, we created the three first mutually exclusive classes. To obtain the three remaining classes, the Finlay and Wilkinson's (1963) method was utilized, with a logarithmic transformation of the simulated values. This transformation introduced a high degree of linearization in classes 4, 5 and $6 \sigma^{2} \Psi=0$ (Nascimento et al., 2013).

A maximum error of $1 \%$ was assumed as a threshold for the test set. The data set of cotton genotypes was added to the network for classification.

The ANN training considered a multi-layer perceptron architecture with the following description for topologies with two hidden layers:number of neurons from 8 to 12 for each hidden layer. The activation function was used adopting the linear activation function for output layers. The hidden layers were investigated for adequacy in all possible combinations of logistic functions and hyperbolic tangent. The number of training cycles was 3,000 seasons and training function was trainbr-Bayesian Regulation back propagation.

For the ANNs, the data was submitted to analysis with the software Genes (Cruz, 2016) and MATLAB (Beale et al., 2017), as described by Nascimento et al. (2013).

\section{RESULTS AND DISCUSSION}

The homogeneity of MSEs was below seven for all the characteristics evaluated in the analysis of variance. There was a significant effect for the GxE. This shows the differential behavior of genotypes in the face of environmental oscillations affecting the phenotypic expression of genotypes in the characteristics that were evaluated.

The average yield of all growing seasons was $2258 \mathrm{~kg} \mathrm{ha}^{-1}$, which is $9 \%$ higher than that found by Lima et al. (2016). They obtained means of 1.539-1.894 kg ha-1 when evaluating commercial genotypes of colored-fiber cotton in uncovered soils. This demonstrates the genetic potential of the genotypes and their effect on cotton yield.

The values of yield coefficients of variation (CV) were considered acceptable in this study (up to $28.54 \%$ ) since these are quantitative characteristics that are greatly influenced by the environment. Most environment pairs (50\%) were classified as complex type interactions. This causes problems for genetic improvement by making it difficult to identify and recommend superior genotypes for all environments (Table 2).

Table 2 displays the decomposition of the GxE interaction into simple (below 50\%) and complex parts (above 50\%).

Table 2. Estimates of the simple parts resulting from interaction decomposition between 12 cotton genotypes and pairs of environments.

\begin{tabular}{cc}
\hline Environments & Yield $\left(\mathbf{k g ~ h a ~}^{\mathbf{- 1})}\right.$ \\
\hline $2013 / 14 \times 2014 / 15$ & 70.81 \\
$2013 / 14 \times 2015 / 16$ & 58.20 \\
$2013 / 14 \times 2016 / 17$ & 83.54 \\
$2014 / 15 \times 2015 / 16$ & 3.14 \\
$2014 / 15 \times 2016 / 17$ & 10.92 \\
$2015 / 16 \times 2016 / 17$ & 11.42 \\
\hline
\end{tabular}


Two negative values were found in the decomposition of the GxE interaction between pairs. Negative results are justified by the lack of correlation between genotype averages in these environments.

The decomposition of interaction demonstrates the need to analyze genotype adaptability and stability. Our study demonstrates the behavior of genotypes in the face of environmental oscillations and reveals genotypes with predictable and responsive behavior to environmental stimuli.

Stability and adaptability measures, by the Eberhart and Russell (1966) method (Table 3) for yield, showed that genotypes UFUJP-01, UFUJP-08, UFUJP-09, UFUJP-10, UFUJP-16, and UFUJP-17 were not significantly different $\left(\beta_{1}=1\right)$. Therefore, these genotypes were classified as having broad adaptability, which demonstrates their enhanced response to environmental stimuli. In terms of stability, these genotypes demonstrate predictability in relation to environmental stimuli, hence they are adapted and stable according to this method. The predictability factor presented high statistical reliability since all $\mathrm{R}^{2}$ values were above $90 \%$.

Table 3. Estimated coefficients estimation of $\beta 0, \beta 1 i$ and $\sigma^{2}$ di using the Eberhart and Russell method (1966) for seed cotton yield (kg ha-1) of 12 genotypes evaluated in four environments 2013/2014, 2014/2015, 2015/2016, and 2016/2017 growing seasons.

\begin{tabular}{|c|c|c|c|c|}
\hline Genotype & Average & $\mathbf{B}_{1}$ & $\sigma_{\mathrm{di}}^{2}$ & $\mathbf{R}^{2}(\%)$ \\
\hline $\begin{array}{l}\text { UFUJP-01 } \\
\end{array}$ & 1842.87 & $0.99^{\text {ns }}$ & $-28274.12^{\mathrm{ns}}$ & 96.66 \\
\hline UFUJP-02 & 2342.64 & $0.99^{\text {ns }}$ & $329376.36 *$ & 82.06 \\
\hline UFUJP-05 & 1845.62 & $0.64 *$ & $102076.19^{\mathrm{ns}}$ & 80.76 \\
\hline UFUJP-08 & 2032.59 & $0.92^{\mathrm{ns}}$ & $34255.80^{\mathrm{ns}}$ & 92.87 \\
\hline UFUJP-09 & 2283.07 & $1.17^{\mathrm{ns}}$ & $-8462.08^{\mathrm{ns}}$ & 96.94 \\
\hline UFUJP-10 & 2129.19 & $1.03^{\text {ns }}$ & $124381.56^{\mathrm{ns}}$ & 90.60 \\
\hline UFUJP-11 & 2203.75 & $0.68 *$ & $-66318.54^{\mathrm{ns}}$ & 96.95 \\
\hline UFUJP-13 & 1829.41 & $0.68 *$ & $465810.49 * *$ & 61.85 \\
\hline UFUJP-16 & 2364.50 & $1.02^{\mathrm{ns}}$ & $-85000.68^{\text {ns }}$ & 99.52 \\
\hline UFUJP-17 & 2494.81 & $1.23^{\mathrm{ns}}$ & $-8378.17^{\mathrm{ns}}$ & 97.23 \\
\hline BRS-RUBI & 2908.46 & $1.58^{*}$ & $747766.81 * *$ & 85.58 \\
\hline BRS-TOPÁZIO & 2829.15 & $1.04^{\mathrm{ns}}$ & $670632.70^{* * *}$ & 74.01 \\
\hline
\end{tabular}

$* * \mathrm{P}<0.01 ; * \mathrm{P}<0.05 ; \mathrm{ns}=$ not significant by the $\mathrm{F}$ test for $\beta_{1}$ and test $\mathrm{T}$, respectively

The highest yield averages of Promalg genotypes were obtained by genotypes UFUJP16 and UFUJP-17. These genotypes are often recommended because they present relative superiority in terms of yield when used in this environment. The controls presented higher productivities; however, with low predictability.

The UFUJP-13 genotype is not useful in these environments because it did not demonstrate stability and had a low $\mathrm{R}^{2}$ value $(61.85 \%)$. The control $\mathrm{RC}$ displayed the highest yield among the genotypes and $\beta$ higher than 1 . Consequently, $\mathrm{RC}$ is a genotype with specific 
adaptability to favorable environments. However, stability analysis of RC presented low predictability, which indicates inconsistent superiority in these environments.

The maximum specific adaptation by the Centroid method is not the genotype that shows good performance in favorable or unfavorable environment groups, but rather the individual that demonstrates maximum values for certain environment groups (favorable or unfavorable) and minimum values for the other environment (Rocha et al., 2005). In Table 4, $58 \%$ of genotypes were classified as having high overall adaptability and high phenotypic stability for yield, that is, high predictability to environmental stimuli.

Table 4. Establishment of ideotypes, calculated by the Centroid method, for yield $\left(\mathrm{kg} \mathrm{ha}^{-1}\right)$ of cotton genotypes, evaluated in fourenvironments2013/2014, 2014/2015, 2015/2016, and 2016/2017 growing seasons..

\begin{tabular}{lccccccccc}
\hline Genotypes & Averages & Classification & I & II & III & IV & V & VI & VII \\
\hline UFUJP-01 & 1842.88 & V & 0.07 & 0.08 & 0.15 & 0.23 & 0.24 & 0.08 & 0.16 \\
UFUJP-02 & 2342.64 & V & 0.09 & 0.10 & 0.12 & 0.12 & 0.26 & 0.10 & 0.22 \\
UFUJP-05 & 1845.63 & IV & 0.06 & 0.06 & 0.24 & 0.28 & 0.16 & 0.06 & 0.14 \\
UFUJP-08 & 2032.60 & V & 0.07 & 0.07 & 0.14 & 0.17 & 0.29 & 0.07 & 0.18 \\
UFUJP-09 & 2283.07 & V & 0.09 & 0.10 & 0.09 & 0.09 & 0.36 & 0.10 & 0.18 \\
UFUJP-10 & 2129.20 & V & 0.08 & 0.08 & 0.12 & 0.14 & 0.31 & 0.08 & 0.19 \\
UFUJP-11 & 2203.76 & VII & 0.06 & 0.06 & 0.14 & 0.11 & 0.25 & 0.06 & 0.31 \\
UFUJP-13 & 1829.41 & IV & 0.06 & 0.06 & 0.22 & 0.31 & 0.15 & 0.06 & 0.13 \\
UFUJP-16 & 2364.51 & V & 0.06 & 0.06 & 0.07 & 0.07 & 0.50 & 0.07 & 0.18 \\
UFUJP-17 & 2494.81 & V & 0.12 & 0.13 & 0.08 & 0.09 & 0.26 & 0.14 & 0.18 \\
BRS-RUBI & 2908.46 & VI & 0.18 & 0.25 & 0.06 & 0.06 & 0.10 & 0.26 & 0.09 \\
BRS-TOPÁZIO & 2829.15 & I & 0.18 & 0.14 & 0.09 & 0.08 & 0.16 & 0.16 & 0.18 \\
\hline
\end{tabular}

I: High overall adaptability; II: Specific adaptability to favorable environments; III: Specific adaptability to unfavorable environments; IV: Poorly adapted; V: High overall adaptability; VI: Specific adaptability to favorable environments; VII: Specific adaptability to unfavorable environments.

The UFUJP-05 and UFUJP-13 genotypes were classified as poorly stable and poorly adaptable, therefore should not be recommended. The UFUJP-11 genotype was classified as specifically adaptable to unfavorable environments and has potential for inclusion in areas with low technology input or unfavorable biotic and abiotic conditions because, even under these conditions, it is prone to obtain good productivity results.

By analyzing the results, we found that the methods of analysis are complementary. Moreover, a joint analysis with the Centroid and Eberhart and Russel (1966) methods increases the reliability in selection and recommendation of cultivars.

The ANN's method obtained 92\% concordance with the method of Eberhart and Russell (1966) by using the concept of classes in the interpretation of adaptability and stability (Table 5). For stability, $75 \%$ of the genotypes changed to a different classification and were not coincident. On the other hand, UFUJP-05, UFUJP-08 and UFUJP-11were unique genotypes that did not display differential behavior among methods.

Table 5. Average yield and classification using the artificial neural networks method, for seed cotton yield (kg ha ${ }^{1}$ ) of 12 genotypes evaluated in four environments 2013/14, 2014/15, 2015/16, and 2016/17.

\begin{tabular}{lcc}
\hline Genotype & Average & Class \\
\hline UFUJP-01 & 1842.87 & 1 \\
UFUJP-02 & 2342.64 & 4 \\
UFUJP-05 & 1845.62 & 6 \\
UFUJP-08 & 2032.59 & 4 \\
UFUJP-09 & 2283.07 & 1 \\
UFUJP-10 & 2146.89 & 4 \\
UFUJP-11 & 2203.75 & 3 \\
UFUJP-13 & 1847.81 & 6 \\
UFUJP-16 & 2364.50 & 1 \\
UFUJP-17 & 2494.81 & \\
BRS-Rubi & 2908.46 & \\
BRS-Topázio & 2829.15 & 5 \\
\hline
\end{tabular}


The low value for stability is due to a divergence between methods; the Eberhart and Russell method (1966) defines the concept of stability as invariance (Nascimento et al., 2013), whereas the ANNs capture complex characteristics of input data using the Finlay-Wilkinson concept (1963) to estimate stability (Teodoro et al., 2015). It is also important to consider that ANNs establish a $\mathrm{R}^{2}$ reference for predictability, with values greater than or equal to $80 \%$, differently than the method of Eberhart and Russell (1966).

Ventura (2012) found a 26\% match for stability between the methods Best Linear Unbiased Prediction (BLUP) and ANNs. Teodoro (2015) found a higher similarity for stability between the ANN's and Eberhart and Russell (1966), with a 70\% accuracy. Barroso (2013) observed an 83\% similarity between the ANNs and Eberhart and Russell (1966). Nascimento et al. (2013), when analyzing 74 genotypes of alfalfa, found 89 and $77 \%$ coincidence between the adaptability and stability classifications, respectively, comparing the methods.

The inconsistency of the Eberhart and Russell (1966) method, when using a small number of environments ( $\mathrm{n}<10)$, may cause failure to reject false null hypotheses. The ANN's can be an alternative to this limiting low number of environments (Nascimento et al., 2013), since they have a capacity of self-learning. The ANN's, however, would need more validations (Teodoro et al., 2015).

It should be emphasized that the ANN's method also recorded a high agreement (75\%) with the centroid method, when we analyzed adaptability. Nevertheless, there was a divergence between the methods when analyzing genotypes UFUJP-05 and UFUJP-13.Both genotypes were classified as adaptive or of minimal adaptability by the centroid method, and both were also classified as adaptive to an unfavorable environment with high predictability by the ANNs. Another divergence related to genotype UFUJP-17, which registered a high overall adaptability by the centroid method, but changed its classification with the ANNs method to specific adaptability in favorable environments with low predictability.

The Centroid and Eberhart and Russell methods (1966) complement and reinforce each other in the prediction of the results. Similarities in the results obtained with these methods were found for the genotypes UFUJP-02, UFUJP-08, UFUJP-13, UFUJP-16, and UFUJP-17, with a coincidence of $83.3 \%$. The only exceptions were UFUJP-10 and UFUJP11. Farias (2016), when analyzing adaptability and stability in maize hybrids, also found similarities between the Centroid and Eberhart and Russell (1966) methods.

It is important to know the performance of the genotypes in the environments. From the average grouping (Table 6), the 2013/2014 crop obtained the best yield averages, standing out as the best for the phenotypic expression of the genotypes. This can be explained by the good conditions of temperature and precipitation $(726 \mathrm{~mm})$, above the minimum required by the crop $(720 \mathrm{~mm})$, and well distributed during the crop cycle. The low precipitation in the post-emergence phase and the gradual increase in the flowering bud and boll filling phases were ideal for obtaining high yields (Borém; Freire, 2014). 


\begin{tabular}{|c|c|c|c|c|}
\hline Genotype & $2013 / 2014$ & $2014 / 2015$ & $2015 / 2016$ & $2016 / 2017$ \\
\hline UFUJP-01 & $2501.66 \mathrm{Ac}$ & $131.26 \mathrm{Ba}$ & $2157.08 \mathrm{Aa}$ & $2628.56 \mathrm{Ac}$ \\
\hline UFUJP-02 & $3478.12 \mathrm{Ab}$ & $687.08 \mathrm{Ca}$ & $3135.62 \mathrm{Aa}$ & $2069.73 \mathrm{Bc}$ \\
\hline UFUJP-05 & $1972.50 \mathrm{Ad}$ & $647.71 \mathrm{Ba}$ & $2266.04 \mathrm{Aa}$ & $2496.26 \mathrm{Ac}$ \\
\hline UFUJP-08 & $2681.25 \mathrm{Ac}$ & $409.38 \mathrm{Ba}$ & $2743.96 \mathrm{Aa}$ & $2295.79 \mathrm{Ac}$ \\
\hline UFUJP-09 & $3630.00 \mathrm{Ab}$ & $381.04 \mathrm{Ca}$ & $2342.91 \mathrm{Ba}$ & $2778.33 \mathrm{Bc}$ \\
\hline UFUJP-10 & $2983.33 \mathrm{Ac}$ & $332.76 \mathrm{Ba}$ & $2969.17 \mathrm{Aa}$ & $2231.53 \mathrm{Ac}$ \\
\hline UFUJP-11 & $2841.87 \mathrm{Ac}$ & $1050.62 \mathrm{Ba}$ & $2572.08 \mathrm{Aa}$ & $2350.44 \mathrm{Ac}$ \\
\hline UFUJP-13 & $1687.50 \mathrm{Bd}$ & $486.88 \mathrm{Ca}$ & $2664.79 \mathrm{Aa}$ & 2499.31 Ac \\
\hline UFUJP-16 & $3229.16 \mathrm{Ac}$ & $616.87 \mathrm{Ba}$ & $2642.50 \mathrm{Aa}$ & $2969.48 \mathrm{Ac}$ \\
\hline UFUJP-17 & $3689.58 \mathrm{Ab}$ & $449.37 \mathrm{Ca}$ & $2529.79 \mathrm{Ba}$ & $3310.48 \mathrm{Ab}$ \\
\hline BRS-Rubi & $4670.00 \mathrm{Aa}$ & $387.92 \mathrm{Ca}$ & $2300.00 \mathrm{Ba}$ & $4275.93 \mathrm{Aa}$ \\
\hline BRS-Topázio & $4665.00 \mathrm{Aa}$ & $1303.33 \mathrm{Ca}$ & $2401.46 \mathrm{Ba}$ & $2946.81 \mathrm{Bc}$ \\
\hline
\end{tabular}

Averages followed by the same capital letter (horizontally) or the same lowercase letter (vertically) do not differ by Scott-Knott's test at 5\% probability.

The 2014/2015 harvest presented environmental conditions that resulted in lower yield averages for the genotypes. This result was in part due to a severe attack of Alabama argillacea (Noctuidae) in the most injury susceptible period, which is the formation of bolls. (Rosolen, 2001). The insect injury promoted significant losses of leaf area and, consequently, a decrease in the production of photo assimilates. Factors that cause unbalance in the synthesis and arrangement of carbohydrates will have a direct effect on final yield, strongly influencing the filling of the fruits (Zhao et al., 2005; Snider et al., 2009; Yeates et al., 2010). During this season, there was also water stress during the crop cycle (only $679 \mathrm{~mm}$ ).

The 2015/2016 crop season presented inferior results compared to environments 1 and 4 , which can be explained by the decrease in precipitation 90 days after emergence, overlapping with the period of filling of the bolls. According to Echer (2014), the lack of rain during this period reduces the production of carbohydrates, which decreases yield, since the younger fruits will abort to supply the demand of the older bolls. Another relevant fact was that average temperatures $\left(22^{\circ} \mathrm{C}\right)$ were not adequate for the reproductive period, which requires temperatures of $28^{\circ} \mathrm{C}$ (ECHER, 2014).

In the 2016/2017 season, the yield decrease was strongly influenced by the high incidence of the cotton boll weevil (Anthonomus grandis), the main pest of the crop. The season precipitation displayed a $20 \%$ lower volume $(555 \mathrm{~mm})$ than that recommended to complete the cycle $(720 \mathrm{~mm})$. Water stress induces the plant to prioritize the growth of larger bolls, resulting in greater flower abortion. Moreover, the deficit causes stomatal closure to reduce water loss. Stomatal closure, in turn, decreases the $\mathrm{CO}_{2}$ input and leads to a decrease in photosynthesis, higher photorespiration, and lower energy efficiency (Loka et al., 2011; Echer, 2014).

Another observation on season is that the crop did not reach the necessary degreedays in 2016/2017. From emergence to harvest, 1622 degree days were registered, much less than the 1970 degree days that cotton reaquires to fully develop. The genotypes UFUJP-17 and BRS-Topázio standed out as the ones with the largest yield potential in all the environments evaluated. In contrast, the genotype UFUJP-13 was not productive under these environmental conditions, and it presented the lowest yield averages. 


\section{CONCLUSIONS}

The GxE interaction for yield-related characters is complex in nature.

Genotypes UFUJP-02 and UFUJP-17 demonstrated the greatest yield potentials among the PROMALG genotypes, with stability and adaptability byall methods.

The UFUJP-11 genotype can be recommended to small producers because it presents specific adaptability to unfavorable environments.

There is concordance between the Centroid method and the Eberhart and Russell method when both are compared with the ANN's method for adaptability.

The similarity of the results confers a greater reliability power to the breeder, avoiding errors in the selection of genotypes adapted to the region.

\section{ACKNOWLEDGMENTS}

The authors thank FAPEMIG (Fundação de Amparo à Pesquisa de Minas Gerais), CNPq (Conselho Nacional de Desenvolvimento Científico e Tecnológico), and The Cotton Breeding Program of UFU for assistance and financial support.

\section{AUTHOR CONTRIBUTIONS}

Conceptualization, Writing and Editing, Data Analysis: Cardoso D. B. O.; Conceptualization: Silva Júnior E. G., Reis M. C., Conceptualization and Data Analysis: de Sousa L. B., Data acquisition: Falco L. M. de S.; Mamede M. C., Machado B.Q. V.; Paiva T. S; Gundim C. P., Writing and Editing: Alves G. A., de Araújo L. P.

\section{REFERENCES}

Barroso LMA, Nascimento M, Nascimento ACC, Silva FF, Ferreira RDP. (2013). Uso do Método de Eberhart e Russell como informação a priori para aplicação de Redes Neurais Artificiais e Análise Discriminante visando a classificação de genótipos de alfafa quanto à adaptabilidade e estabilidade fenotípica. Rev. Bras. Biometria 31: 176188.

Beale MH, Hagan M, Demuth HB. (2017). Neural network performance-MATLAB cross entropy-the MathWorks United Kingdom. Mathworks. Com.

Cruz CD. (2016). Genes Software-extended and integrated with the R, Matlab and Selegen. Acta Sci. Agron. 38: 547552.

Cruz CD, Regazzi AJ, Carneiro PCS. (2014). Modelos Biométricos aplicados ao melhoramento genético. 3. ed. Viçosa: Editora UFV.

Cruz CD, Castoldi FL. (1991). Simple and complex decomposition in parts of the genotypes $\mathrm{x}$ environments interation = Decomposição da interação genótipos x ambientes em partes simples e complexa. Rev. Ceres. 38: 422-430

Eberhart SA, Russell WA. (1966). Stability parameters for comparing varieties. Crop. Sci. 6: 36-40.

Echer FR. (2014). O algodoeiro e os estresses abioticos: temperatura, luz, água e nutrientes. IMAmtp. 63-79.

Faria SV, Luz SL, Rodrigues MC, Carneiro JES, Carneiro PCS and Lima RO. (2017). Adaptability and stability in commercial maize hybrids in the southeast of the State of Minas Gerais, Brazil. Rev. Ciên. Agron. 48: 347-357.

Finlay KW, Wilkinson GN. (1963). The analysis of adaptation in a plant-breeding programme. Aust. J. Agric. Res. 14: $742-754$.

Haykin S. (2009). Neural networks and learning machines. 3rd ed. New York: Prentice Hall, 936p.

Júnior EGS, Cardoso DBO, Reis MC, Nascimento AFO, Bortolin DI, Martins MR, Sousa LB. (2017). Cotton genotypes selection through artificial neural networks. Genet. Molec. Res. 16: gmr16039798.

Lima GS, Dias AS, Ghey HR, Soares LA Dos A, Andrade EMG. (2018). Saline water irrigation and nitrogen fertilization on the cultivation of colored fiber cotton. Rev. Caatinga 31: 151-160.

Loka DA, Oosterhuis DM, Ritchie GL. (2011). Water-deficit stress in cotton. Stress physiology in cotton.In: Oosterhuis DM (ed.) Stress physiology in cotton, vol7. The Cotton Foundation, Cordova, pp 37-72. 
Nascimento M, Cruz CD, Campana ACM, Tomaz RS, Salgado CC, Ferreira R De P. (2009). Alteração no método centroide de avaliação da adaptabilidade genotípica. Pesqui. Agropecu. Bras. 44: 263-269.

Nascimento M, Peternelli LA, Cruz CD, Nascimento ACC, Ferreira RDP, Bhering LL, Salgado CC. (2013). Artificial neural networks for adaptability and stability evaluation in alfalfa genotypes. Crop. Breed. Appl. Biotechnol. 13: $152-156$.

Rao RC. (1962). Advanced statistical methods in biometrics research. New York: John Wiley and Sons, 390p.

Reis MC, Cardoso DBO, Silva Júnior EG, Gomes BC, Pereira LTG, Gomes DA, Sousa LB. (2017). Correlation among traits as criterion of cotton genotypes indirect selection. Genet. Mol. Res. 16: 3-12.

Rocha BR, Muro-Abad JI, Fernandes AE, Cruz CD. (2005). Avaliação do método centróide para estudo de adaptabilidade ao ambiente de clones de Eucalyptus grandis. Ci. Fl. 15: 255-266..

Rosolem CA. (2001). Ecofisiologia e manejo da cultura do algodoeiro. Inform. Agron. 95: 1-9.

Snider JL, Oosterhuis DM, Skulman BW, Kawakami EM. (2009). Heat stress-induced limitations to reproductive success in Gossypium hirsutum. Physiol. Plant 137: 125-138.

Teodoro PE, Barroso LMA, Nascimento M, Torres FE, Sagrilo E, Dos Santos A, Ribeiro LP. (2015). Redes neurais artificiais para identificar genótipos de feijão-caupi semiprostrado com alta adaptabilidade e estabilidade fenotípicas. Pesq. Agropec. Bras. 50: 1054-1060.

USDA, United States Department of Agriculture. Cotton: World Markets and Trade. Available in https://apps.fas.usda.gov/psdonline/circulars/cotton.pdf >. Accessed in 04/27/2018.

Ventura RV, Silva MA, Medeiros TH, Dionello NL, Madalena FE, Fridrich A B, Felipe VPS. (2012). Use of artificial neural networks in breeding values prediction for weight at 205 days in Tabapuã beef cattle. Arq. Bras. Med. Vet. Zootec. 64: 411-418.

Yeates SJ, Constable GA, Mccumstie T. (2010). Irrigated cotton in the tropicaldry season. I: Yield, its components and crop development. Field Crops. Res. 116: 278-289.

Zhao D, Reddy KR, Kakani VG, Koti S, Gao W. (2005). Physiological causes of cotton fruit abscission under conditions of high temperature and enhanced ultraviolet-B radiation. Physiol. Plant 124: 189-199. 